\title{
Outcome of Multiple Pregnancy Conceived Spontaneously Versus by Assisted Reproductive Therapy (Comparative Study)
}

\author{
Nabila Salim Mohammed ${ }^{1} \&$ Faten Ibrahim Elsebeiy ${ }^{2}$ \\ ${ }^{1,2}$ lecturers of Obstetrics \& Gynecological Nursing, Faculty of Nursing, Zagazig University.
}

\begin{abstract}
Background: There is a continuous controversy regarding the obstetric perinatal outcome of multiple pregnancies conceived after assisted reproductive techniques (ART). There is an ongoing discussion whether theses parameters may show poorer results as compared to spontaneous conception.

Aims: of the present study wereto compare the perinatal outcome in spontaneous multiple pregnancies compared to those conceived by ART and to design a booklet to orient the parturient women included in the study about spontaneously conceived and ART conceived multiple pregnancies.

Design: A prospectivecohort observational study was used.

Setting: The study was conducted at the labor ward at labor and child hood hospital, Zagazig University hospital. Subjects: Group A consisted of 83 parturient women with spontaneously conceived multiple pregnancies and group B which consisted of 27 parturient women with multiple pregnancies conceived by ART who were admitted to the study setting within a period of one year from January to December, 2015.

Tools: Data collection tool consisted of 3 parts, structured interview questionnaire, labor record and neonatal record.

Results: Group B were significantly complicated with threatened abortion and placenta previa than group A (24.0\%\& $24.0 \%$ VS. $7.1 \%$ \& $2.4 \%$ respectively). Premature rupture of membrane and severe preeclampsia were statistically significant main indications of emergency cesarean delivery in group A compared to group $B$, while placenta previa was a statistically significant amin indication for emergency CS in group B compared to group A $(P=0.032)$. As regards neonatal outcome, there were a statistically significant increase in the neonatal intensive care unit admission and still birth in group B compared to group A $(64.0 \%$ \& $22.0 \% \mathrm{VS} .46 .4 \%$ \& $2.9 \%$ respectively).
\end{abstract}

Conclusion: Based on the findings of the study, When compared to spontaneously conceived twins, ARTconceived twins are more or less similar to those conceived spontaneously.

Recommendation: Multiple pregnancy in general whether conceived spontaneously or by ART techniques require proper antenatal, intra-natal and postnatal care as it poses several risks on both mother and fetus.

Keywords: Multiple pregnancy, spontaneous pregnancy, assisted conception, outcome.

\section{Introduction}

When in vitro fertilization (IVF) was first introduced into clinical practice, there were no data available on its safety. The first reports on the safety of IVF were published by Cohen [1] and the American Society for Reproductive Medicine and Society of Assisted Reproductive Technology [2].

In recent years, an increasingly large proportion of deliveriesfollowing ART have been multiple pregnancies[3]. The most important reason for the increasedrates of adverse perinatal outcomes observed in ART pregnanciesis multifetal pregnancies. In addition, even in singletonpregnancies, ART may be associated with an increasedrisk of adverse perinatal outcomes, including increased ratesof labor induction and Caesarean delivery. A small but significantincrease in congenital structural anomalies andchromosomal abnormalities has also been observed in singletonART pregnancies in studies including pregnancy terminations. [4,5]

Multiple gestational pregnancies are nowrecognized as a major epidemiological concernassociated with both assisted reproductivetechnologies (ART) and ovulation inductiontherapies. Today by far the greatest number ofmultiple gestation pregnancies is due to some typeof assisted procreation. The number of twinsassociated with ART has been estimated to be ashigh as 32\% [6]

This trend has a great degree ofimportance to clinicians involved in assistedreproduction since studies have shown that notonly is multiple gestations more common in ARTconceptions, but that when compared tospontaneous conceptions (SC), ART conceptionshave demonstrated a higher chance of detrimentaleffects for both mothers and neonates $[7,8]$.

Research Design:

\section{Subjects and Methods}

A prospective cohort observational study was used to achieve the aim of the current study. 
Aims of the study: to compare the perinatal outcome in spontaneous multiple pregnancies compared to those conceived by ART and to design a booklet to orient the parturient women included in the study about spontaneously conceived and ART conceived multiple pregnancies.

\section{Setting:}

The current study was conducted at labor ward of labor and childhood hospital, Zagazig university hospitals.

\section{Subjects:}

The parturient women with multiple pregnancies at a period of one year from January to December 2015, were recruited in the study. The total number was (112) parturient women with multiple pregnancies and they were divided into two groups:

Group A: Consisted of ( 83 ) conceived spontaneously

Group B: Consisted of (27) conceived by one of the assisted reproductive technologies.

The researchers selected The parturient women with multiple pregnancies who met the following inclusion criteria: no medical disorders were encountered before pregnancy as diabetes mellitus, hypertension, heart disease, hepatic or renal disease.

\section{Tools of Data Collection:}

\section{1- Structured Interview Questionnaire:}

It included data related to age, parity, previous multiple pregnancy, medical and obstetric complications encountered during previous multiple pregnancy. It also included current pregnancy history as method of conception, type of the assisted reproductive technology used, number of fetus and current pregnancy complications.

\section{2- Labor Record:}

It included data related to the gestational age at the onset of delivery, the mode, route of delivery, types of CS and its indications and occurrence of postpartum hemorrhage.

\section{3- Neonatal Record:}

It included data related to each newborn as APGAR score at the $1^{\text {st }}$ and $5^{\text {th }}$ minute, need for resuscitation, birth weight, admission to NICU, gross congenital anomalies, still birth and neonatal death.

\section{Content Validity and Reliability:}

Tools were submitted to a panel of five experts in the field of maternity nursing and obstetrics medicine to test the content validity. Modifications were carried out according to the panel judgment. Reliability test was assessed by applying the tools on 10 women.

Pilot Study:

A pilot study was carried out on $10 \%$ of parturient women with multiple pregnancies and they were not included in the study sample to test the study tools in terms of clarity and feasibility and necessary modifications were done.

\section{Field Work:}

Data collection took a period of one year from January to December 2015. After getting the official permission, the pilot testing of the study tools was done and analyzed. The initial assessment was done by the on duty physician with the assistance of the researchers and the parturient women were allocated to either group A and group B afterwards. The delivery was conducted at labor and childhood hospital with the assistance of the on duty physician. The mode of delivery and any complications following delivery were assessed. Neonatal assessment was done through measuring the APGAR score and finding out any abnormality that needed admission to the neonatal intensive care unit.

\section{Administrative and ethical considerations:}

An official permission was obtained by submission of an official letter from the faculty of nursing to the responsible authorities of the study setting to obtain the permission for data collection. Nursing and medical staff responsible for the patients were approached to gain their cooperation. All ethical issues were taken into consideration during all phases of the study. The aim of the study was explained to every woman before participation, which was totally voluntary. Women were assured that the study maneuver will cause no actual or potential harm on them and professional help was provided whenever needed. Women were notified that they 
can withdraw at any stage of the research; also they assured that the information obtained during the study will be confidential and used for the research purpose only.

\section{Statistical analysis:}

After collection of data, it was revised, coded and fed to statistical software SPSS version 16. The statistical analysis used $\mathrm{T}$ test with alpha error $=0.05$. Microsoft office excel software was used to construct the needed graphs. After data coding the following data manipulations were done. After data manipulation was done all numeric data were expressed in the form of range (minimum to maximum), mean and standard deviation (SD). Categorical data were expressed in the form of frequencies and percentages.

\section{Results}

Table 1) Distribution of the study subject according to age and obstetrics history

\begin{tabular}{|c|c|c|c|c|c|c|c|}
\hline \multirow[t]{3}{*}{ Characteristics } & \multicolumn{4}{|c|}{ Group } & \multirow{2}{*}{\multicolumn{2}{|c|}{ Total }} & \multirow[t]{3}{*}{$M C P$} \\
\hline & \multicolumn{2}{|c|}{$\begin{array}{l}\text { Spontaneous } \\
\text { conception }\end{array}$} & \multicolumn{2}{|c|}{$\begin{array}{l}\text { Assisted } \\
\text { conception }\end{array}$} & & & \\
\hline & No & $\%$ & No & $\%$ & No & $\%$ & \\
\hline \multicolumn{7}{|l|}{ Age (years) } & \multirow[t]{4}{*}{$0.001 *$} \\
\hline - $<25$ & 37 & 43.5 & 3 & 12.0 & 40 & 36.4 & \\
\hline - $25-35$ & 41 & 48.2 & 14 & 56.0 & 55 & 50.0 & \\
\hline - $35+$ & 7 & 8.2 & 8 & 32.0 & 15 & 13.6 & \\
\hline Mean \pm SD & \multicolumn{6}{|c|}{$35.58 \pm 6.57$} & \\
\hline \multicolumn{7}{|l|}{ Gravida } & \multirow[t]{4}{*}{$0.001^{*}$} \\
\hline Primigravida & 26 & 30.6 & 18 & 72.0 & 44 & 40.0 & \\
\hline $2-3$ & 42 & 49.4 & 3 & 12.0 & 45 & 40.9 & \\
\hline $4-8$ & 17 & 20.0 & 4 & 16.0 & 21 & 19.1 & \\
\hline \multicolumn{7}{|l|}{ Parity } & \multirow[t]{4}{*}{$0.001 *$} \\
\hline Nullipara & 27 & 31.8 & 18 & 72.0 & 45 & 40.9 & \\
\hline Primipara & 29 & 34.1 & 6 & 24.0 & 35 & 31.8 & \\
\hline . $2-5$ & 29 & 34.1 & 1 & 4.0 & 30 & 27.3 & \\
\hline Abortion & & & & & & & \multirow[t]{3}{*}{$0.476 !$} \\
\hline - $\quad$ No & 62 & 72.9 & 20 & 80.0 & 82 & 74.5 & \\
\hline - Yes & 23 & 27.1 & 5 & 20.0 & 28 & 25.5 & \\
\hline \multicolumn{7}{|c|}{ Previous multiple pregnancy } & \\
\hline - Yes & 13 & 15.3 & 1 & 4.0 & 14 & 12.7 & \\
\hline - $\quad$ No & 72 & 84.7 & 24 & 96.0 & 96 & 87.3 & \\
\hline
\end{tabular}

MCP: Mont Carlo exact probability !: Fisher exact probability $* \mathrm{P}<0.05$ (significant)

Table 1) Shows comparison of age and obstetrics history among spontaneous and assisted conception groups, there were $8.2 \%$ of spontaneous group were more than $35 y$ years compared to $32 \%$ in assisted conception group observed were a statistically significant. Regarding number of gravida, number of parity as majority of assisted conception group were primigravida and null parity $(72 \%, 72 \%$ respectively).

Table 2) Obstetric complications encountered during previous multiple pregnancy

\begin{tabular}{|c|c|c|c|c|c|c|c|}
\hline \multirow{3}{*}{$\begin{array}{l}\text { Obstetric } \begin{array}{r}\text { complications } \\
\text { encountered during } \\
\text { multiple pregnancy }\end{array} \\
\text { Previous }\end{array}$} & \multicolumn{4}{|c|}{ Group } & \multirow{2}{*}{\multicolumn{2}{|c|}{ Total }} & \multirow[t]{3}{*}{ FEP } \\
\hline & \multicolumn{2}{|c|}{$\begin{array}{l}\text { Spontaneous } \\
\text { conception }(n=13)\end{array}$} & \multicolumn{2}{|c|}{$\begin{array}{l}\text { Assisted conception } \\
(\mathrm{n}=1)\end{array}$} & & & \\
\hline & No & $\%$ & No & $\%$ & No & $\%$ & \\
\hline \multicolumn{8}{|l|}{ Previous multiple pregnancy } \\
\hline - $\quad$ Yes & 13 & 15.3 & 1 & 4.0 & 14 & 12.7 & \multirow[t]{2}{*}{0.136} \\
\hline - $\quad \mathrm{No}$ & 72 & 84.7 & 24 & 96.0 & 96 & 87.3 & \\
\hline Threatened abortion & 2 & 15.4 & 0 & 0.0 & 2 & 14.3 & 0.627 \\
\hline Oligohydramnios & 2 & 15.4 & 0 & 0.0 & 2 & 14.3 & 0.627 \\
\hline Preeclampsia & 1 & 7.7 & 0 & 0.0 & 1 & 7.1 & 0.773 \\
\hline Accidental $\mathrm{He}$ & 1 & 7.7 & 1 & 100.0 & 2 & 14.3 & 0.521 \\
\hline Preterm labor & 1 & 7.7 & 0 & 0.0 & 1 & 7.1 & 0.733 \\
\hline $\mathrm{CS}$ & 6 & 46.2 & 0 & 0.0 & 6 & 42.9 & 0.369 \\
\hline Obstructed labor & 1 & 7.7 & 0 & 0.0 & 1 & 7.1 & 0.773 \\
\hline $\mathrm{PPH}$ & 2 & 15.4 & 0 & 0.0 & 2 & 14.3 & 0.627 \\
\hline Admission to NICU & 2 & 15.4 & 0 & 0.0 & 2 & 14.3 & 0.672 \\
\hline
\end{tabular}

!: Mont Carlo exact probability

As regard complication encountered during previous multiple pregnancy table 2 shows that $15.3 \%$ in spontaneous group reported previous multiple pregnancy compared to $4 \%$ in assisted conception group and nonstatistically significant difference observed. between the two study group only one case in assisted conception 
group had accidental hemorrhage during their previous pregnancy this can be explained as majority of assisted conception group where primigravida.

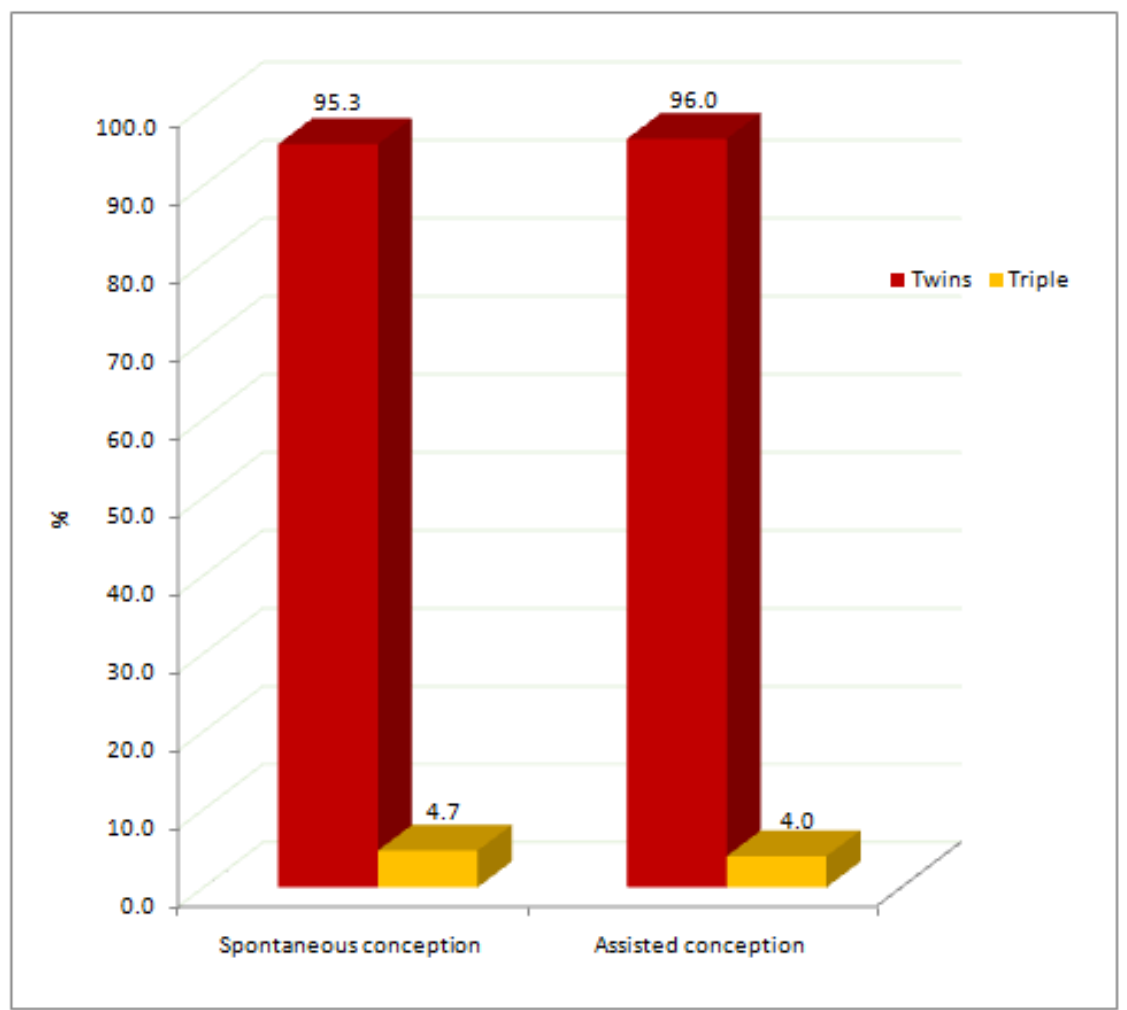

Figure 1) Comparison between number of fetus in both spontaneous conception and assisted conception group.

Regarding number of fetus figure 1 illustrated no difference between spontaneous and assisted conception groups $95.3 \%$ compared to $96 \%$ respectively.

Table 3) Distribution of the study subjectsaccording to complication encounter during present pregnancy and

\begin{tabular}{|c|c|c|c|c|c|c|c|}
\hline \multirow[t]{3}{*}{ Current pregnancy complications } & \multicolumn{4}{|c|}{ Group } & \multirow{2}{*}{\multicolumn{2}{|c|}{ Total }} & \multirow{3}{*}{ FEP } \\
\hline & \multicolumn{2}{|c|}{ Spontaneous conception } & \multicolumn{2}{|c|}{ Assisted conception } & & & \\
\hline & No & $\%$ & No & $\%$ & No & $\%$ & \\
\hline Threatened abortion & 6 & 7.1 & 6 & 24.0 & 12 & 10.9 & $0.017 *$ \\
\hline Oligohydramnios & 2 & 2.4 & 0 & 0.0 & 2 & 1.8 & 0.439 \\
\hline Preeclampsia & 17 & 20.0 & 8 & 32.0 & 25 & 22.7 & 0.208 \\
\hline DM & 6 & 7.1 & 3 & 12.0 & 9 & 8.2 & 0.427 \\
\hline Placenta previa & 2 & 2.4 & 6 & 24.0 & 8 & 7.3 & $0.001 *$ \\
\hline Accidental $\mathrm{He}$ & 2 & 2.4 & 0 & 0.0 & 2 & 1.8 & 0.439 \\
\hline IUFD & 7 & 8.2 & 3 & 12.0 & 10 & 9.1 & 0.565 \\
\hline Preterm labor & 4 & 4.7 & 2 & 8.0 & 6 & 5.5 & 0.524 \\
\hline IUGR & 3 & 3.5 & 0 & 0.0 & 3 & 2.7 & 0.341 \\
\hline PROM & 29 & 34.1 & 5 & 20.0 & 34 & 30.9 & 0.179 \\
\hline Regular ANC & 48 & 56.5 & 25 & 100.0 & 73 & 66.4 & $0.001 *$ \\
\hline Hospital admission for pregnancy complications & 22 & 25.9 & 11 & 44.0 & 33 & 30.0 & $0.050 *$ \\
\hline
\end{tabular}

FEP: Fisher exact probability* $\mathrm{P}<0.05$ (Significant)

Table 3 reveal that there is statistically significant difference between assisted and spontaneous conception group regarding complication encountered during present pregnancy, there were $24 \%$ \& $24 \%$ of assisted group had threatened abortion and placenta previa respectively compared to $7.1 \%$ \&2.4\% in spontaneous group.

As regard antenatal care $100 \%$ of women in assisted conception group were attended to ANC regularly compared to $56.5 \%$ in spontaneous group.Also $44 \%$ of assisted conception group admitted hospital for treatment of complication during pregnancy compared to $25.9 \%$ in spontaneous conception group and difference observed were statistically significant. 
Table 4) Comparison of study subject according to mode of delivery

\begin{tabular}{|c|c|c|c|c|c|c|c|}
\hline \multirow[t]{3}{*}{ Labor data } & \multicolumn{4}{|c|}{ Group } & \multirow{2}{*}{\multicolumn{2}{|c|}{ Total }} & \multirow[t]{3}{*}{$M C P$} \\
\hline & \multicolumn{2}{|c|}{ Spontaneous conception } & \multicolumn{2}{|c|}{ Assisted conception } & & & \\
\hline & No & $\%$ & No & $\%$ & No & $\%$ & \\
\hline \multicolumn{7}{|l|}{ Mode of delivery } & \multirow[t]{3}{*}{0.740} \\
\hline - Normal vaginal delivery & 21 & 24.7 & 7 & 28.0 & 28 & 25.5 & \\
\hline - $\quad$ Cesarean section & 64 & 75.3 & 18 & 72.0 & 82 & 74.5 & \\
\hline Type of CS & & & & & & & \multirow[t]{3}{*}{$0.050 *$} \\
\hline - Emergency CS & 41 & 64.1 & 7 & 38.9 & 48 & 58.5 & \\
\hline - $\quad$ Elective CS & 23 & 35.9 & 11 & 61.1 & 34 & 41.5 & \\
\hline \multicolumn{7}{|l|}{ Indications of emergency CS } & \multirow[t]{7}{*}{$0.032 *$} \\
\hline - $\quad$ Severe PET & 13 & 31.7 & 1 & 14.3 & 14 & 29.2 & \\
\hline - $\quad$ Accidental He & 1 & 2.4 & 0 & 0.0 & 1 & 2.1 & \\
\hline Placenta previa & 6 & 14.6 & 5 & 71.4 & 11 & 22.9 & \\
\hline Oligohydramnios & 2 & 4.9 & 0 & 0.0 & 2 & 4.2 & \\
\hline - $\quad$ PROM & 15 & 36.6 & 0 & 0.0 & 15 & 31.3 & \\
\hline - $\quad$ Fetal distress & 4 & 9.8 & 1 & 14.3 & 5 & 10.4 & \\
\hline \multicolumn{7}{|l|}{ Indications of elective CS } & \multirow[t]{5}{*}{$0.001 *$} \\
\hline - $\quad$ ART & 0 & 0.0 & 8 & 72.7 & 9 & 26.5 & \\
\hline Previous CS & 12 & 52.2 & 0 & 0.0 & 12 & 35.3 & \\
\hline - $\quad$ Malpresentation & 9 & 39.1 & 3 & 27.3 & 12 & 35.3 & \\
\hline - $\quad$ CPD & 1 & 4.3 & 0 & 0.0 & 1 & 2.9 & \\
\hline \multicolumn{7}{|l|}{ GA at the onset of labor } & \multirow[t]{4}{*}{0.162} \\
\hline . $\quad<37$ wks. & 42 & 49.4 & 17 & 68.0 & 59 & 53.6 & \\
\hline - $\quad 37-39$ & 37 & 43.5 & 8 & 32.0 & 45 & 40.9 & \\
\hline - $40+$ & 6 & 7.1 & 0 & 0.0 & 6 & 5.5 & \\
\hline \multicolumn{7}{|l|}{ PPH } & \multirow[t]{3}{*}{$0.970 !$} \\
\hline - Yes & 7 & 8.2 & 2 & 8.0 & 9 & 8.2 & \\
\hline - $\quad$ No & 78 & 91.8 & 23 & 92.0 & 101 & 91.8 & \\
\hline
\end{tabular}

MCP: Mont Carlo exact probability

!: Fisher exact probability $* \mathrm{P}<0.05$ (significant)

Distribution of study subject according to mode of delivery illustrated in table 4 astatically significant difference observed between the two study group as $61.1 \%$ of assisted conception group delivered by CS electively compared to $35.9 \%$ in spontaneous conception group.

Regard indication of C.S astatically significant difference observed between the two study groups as there were $71.4 \%$ and $52.2 \%$ of assisted conception group had placenta previa and previous CS as indication of CS respectively compared to $14.6 \%$ and $0.0 \%$ in spontaneous conception group respectively .

Table 5) Comparison of neonatal outcome between spontaneous and assisted conception group

\begin{tabular}{|c|c|c|c|c|c|c|c|}
\hline \multirow[t]{3}{*}{ Newborn data } & \multicolumn{4}{|c|}{ Group } & \multirow{2}{*}{\multicolumn{2}{|c|}{ Total }} & \multirow[t]{3}{*}{$X^{2}(\mathbf{P})$} \\
\hline & \multicolumn{2}{|c|}{ Spontaneous conception } & \multicolumn{2}{|c|}{ Assisted conception } & & & \\
\hline & No & $\%$ & No & $\%$ & No & $\%$ & \\
\hline Maturity & & & & & & & \multirow[t]{3}{*}{$2.9(0.635)$} \\
\hline - $\quad$ Preterm & 84 & 49.4 & 34 & 68.0 & 118 & 53.6 & \\
\hline - $\quad$ Full term & 86 & 50.6 & 16 & 32.0 & 102 & 46.4 & \\
\hline Resuscitation & & & & & & & \multirow[t]{3}{*}{$2.7(0.529)$} \\
\hline - Yes & 92 & 54.1 & 33 & 66.0 & 125 & 56.8 & \\
\hline No & 78 & 45.9 & 17 & 34.0 & 95 & 43.2 & \\
\hline \multicolumn{8}{|l|}{ Birth weight } \\
\hline . $\quad<1500$ & 34 & 20.0 & 16 & 32.0 & 50 & 22.7 & \multirow[t]{3}{*}{$4.3(0.507)$} \\
\hline $1500-2500$ & 66 & 38.8 & 25 & 50.0 & 91 & 41.4 & \\
\hline - $2500+$ & 70 & 41.2 & 9 & 18.0 & 79 & 35.9 & \\
\hline NICU admission & 79 & 46.4 & 32 & 64.0 & 111 & 50.5 & $5.9(0.028)^{*}$ \\
\hline Congenital anomalies & 2 & 1.17 & 0 & 0.0 & 2 & 0.9 & $0.857 !$ \\
\hline Stillbirth & 5 & 2.9 & 11 & 22.0 & 16 & 7.3 & $0.042 *$ \\
\hline Neonatal death & 5 & 2.9 & 0 & 0.0 & 5 & 2.3 & $0.241 !$ \\
\hline
\end{tabular}

!: Fisher exact probability $* \mathrm{P}<0.05$ (significant)

Table 5 summarizes the distribution of the study subject according to neonatal outcome. In relation to maturity of neonate there $68 \%$ of neonate of assisted conception group were preterm compared to $49.4 \%$ of spontaneous conception group but difference observed statistically insignificant.

Regarding neonatal resuscitation there were no statistically significant difference between the two study group as $54.1 \%$ of spontaneous conception group need resuscitation compared to $66 \%$ assisted conception group. Also table 5 shows that there were a statistically significant observed between spontaneous and assisted conception group neonatal admission to NICU as $64 \%$ of assisted conception group admitted NICU compared to $46.4 \%$ in spontaneous group. 
The same table also shows that there were a statistically significant observed between spontaneous and assisted conception group regarding stillbirth $22 \%$ of assisted conception group were stillbirth compared to $2.9 \%$ in spontaneous conception group.

\section{Discussion}

The incidence of twins has markedly increased since the introduction of IVF/ICSI program. Toepidemic proportions. International registries have documented this increase over time. In the 2002report by the European Society for Reproductive Medicine (ESHRE), the distribution of singleton,twin and triplet deliveries for IVF and ICSI combined was 75.5, 23.2 and 1.3\%, respectively,giving a total multiple delivery rate of $24.5 \%$ [9]. This was only a marginal improvement on the

2001 report, which demonstrated a $25.5 \%$ multiple delivery rates [10].

Aim of the present study wasto compare the perinatal outcomes in spontaneous twins compared with those conceived by ART.

Statistically significant difference observed between the two studied groups regarding maternal age, and obstetric historythere were $8.2 \%$ of spontaneous group were more than 35 years compared to $32 \%$ in assisted conception group observed were a. Regarding number of gravida, number of parity as majority of assisted conception group were primigravida and null parity. The results of the present study are in contrastwith those reported byEskandar, M. 2007 [10]whoreported thatThere was no significant difference in the patients' age, relevant obstetric history with similar numbers of previous pregnancies (gravida) and deliveries (para).

As regard complication encountered during previous multiple pregnancy non-statistically significant difference observed between the two studied groups only one case in assisted conception group had accidental hemorrhage during their previous pregnancy as majority of them were primigravida.

Regarding complication encountered during present pregnancy, there is statistically significant difference between assisted and spontaneous conception group nearly one quarter of assisted group had threatened abortion and placenta previa respectively compared to $7.1 \% \& 2.4 \% \%$ in spontaneous group. This finding was in agreement withBaxi A, Kaushal M(2008) who reported that pregnancy-related complications like antepartumhemorrhage, pregnancy-induced hypertension, gestationaldiabetes, and postpartum hemorrhage were similar in boththe groups and were not statistically Significant.

As regard antenatal care $100 \%$ of women in assisted conception group were attended to ANC regularly compared to $56.5 \%$ in spontaneous group. Also nearly half of assisted conception group admitted hospital for treatment of complication during pregnancy compared to one quarter in spontaneous and difference observed were statistically significant.In the same line Luke et al. 2004 reported that assisted conception was not normally by itself a risk factor adverse outcome.Although in our study pregnancy complications in ART pregnancies are comparable with non-ART twinpregnancies, the ART twin mothers were more likely to be on sick leave or hospitalized during pregnancy. Thiscould be because of increased anxiety and concern for the newborn.

According to mode of delivery astatically significant difference observed between the two study group as $61.1 \%$ of assisted conception group delivered by CS electively compared to $35.9 \%$ in spontaneous conception group. Regard indication of C.S astatically significant difference observed between the two study groups as there were $71.4 \%$ and $52.2 \%$ of assisted conception group had placenta previa and previous CS as indication of CS respectively compared to $14.6 \%$ and $0.0 \%$ in spontaneous conception group respectively.

This finding was in agreement withFilicori Metal. 2005. Reported that the overall cesarean delivery rate his studywas high with the ART group having a higher rate than spontaneous group. Increased operative delivery in twinpregnancy has been defined in many studiesThe cesarean birthrate in ART groupwas signigcant higher than that of spontaneous group.

Investigating relation to maturity of neonate there more than half of neonate of assisted conception group were preterm compared to $49.4 \%$ of spontaneous conception group but difference observed statistically insignificant.

This finding was in agreement withFilicori Metal. 2005who reported that the mean birth weight in ARTtwin pregnancy was signigcant lower than spontaneousconception. Preterm birth is a frequent problem in women whoundergo treatment for infertility. Infertile women seemto have predisposition to giving preterm birth and lowbirth weight babies. Even singleton births resultingfrom ART are associated with an increased risk of lowbirth weight.[5,9]

In the same lineEskandar, M. 2007 reported that there was a trend toward preterm labor with ICSI twins than with naturally conceived twins but no significantdifference between both groups regarding neonatal weight, Apgar score (A/S) and weight of the placenta. Inaddition, the post-natal/ neonatal period was similar in both groups. There was no difference in maternal outcomesin both groups.

Regarding neonatal resuscitation there were no statistically significant difference between the two study group as $54.1 \%$ of spontaneous conception group need resuscitation compared to $66 \%$ assisted 
conception group. Also a statistically significant observed between spontaneous and assisted conception group neonatal admission to NICU as $64 \%$ of assisted conception group admitted NICU compared to $46.4 \%$ in spontaneous group.

In the same line Sutcliffe AG 2002 found that twins conceived by IVF are at signigcant higher risk for prematurityand associated neonatal morbidity and mortality than spontaneously conceived twins. Similarly Daniel et al,2000found that ART-conceived twin pregnancy is at greater risk than non-ART conceived one for pregnancy complications and adverse perinatal outcome.

There were a statistically significant observed between spontaneous and assisted conception group regarding stillbirth $22 \%$ of assisted conception group were stillbirth compared to $2.9 \%$ in spontaneous conception group.In the other hand Baxi A, Kaushal M(2008)reported thatpretermlabor (88.9\% vs. 57.9\%) was more common in study group $(P<0.05)$. Mean gestational age at the time of delivery wasless in ART twin pregnancy than spontaneous pregnancies $(34.51 \pm 3.1$ vs. $36.81 \pm 2.5)$. A signigcant difference wasseen between both groups with respect to the mode of delivery

\section{Reference}

[1]. Cohen J, Mayaux MJ, Guihard-Moscato ML. Pregnancy outcomes after in vitro fertilization. A collaborative study on 2342 pregnancies. Ann N Y Acad Sci. 2005; 541:1-6.

[2]. Assisted reproductive technology in the United States and Canada: 1993 results generated from the American Society for Reproductive Medicine/Society for Assisted Reproductive Technology Registry. FertilSteril. 1995;64:13-21

[3]. US Centers for Disease Control and Prevention. Assisted Reproductive Technology. Available at: <http://www.cdc.gov/reproductivehealth/ ART02/index.htm>. Accessed November 15, 2005.

[4]. European Society of Human Reproduction and Embryology. European IVF Monitoring (EIM). Available at: <http://www.eshre.com/ mc.asp?pageId=496>. Accessed November 15, 2005.

[5]. Health Canada. Assisted Human Reproductive Agency of Canada. Available at:<http://www.hc-sc.gc.ca/ahc-asc/media/nrcp/2005/2005_67bk1_e.html>. Accessed November 30, 2005.

[6]. Society for assisted reproductive technology (SART) and American Society for reproductive medicine (ASRM). Assisted reproductive technology in the United States: 1999 results generated from the ASRM/SART registry. FertilSteril 2002; 78: 918-931.

[7]. Addor V, Snatos-Eggimann B, Fawer CL, Paccaud F, Calame A. Impact of infertility treatments on the health of newborns. FertilSteril. 2009;69:210-215.

[8]. Zuppa AA, Maragliano G, Scapillati ME, Crescimbini B, Tortorolo G.(2001)Neonatal outcome of spontaneous and assisted twin pregnancies. Eur J ObsGynReprod Biol. 2001;95:68-72.

[9]. The European IVF-monitoring programme (EIM) for the European Society of Human Reproduction and Embryology (ESHRE); Andersen AN, Gianaroli L, Felberbaum R, de Mouzon J, Nygren KG. Assisted reproductive technology in Europe, 2002. Results generated from European registers by ESHRE. Hum Reprod. 2006 Jul;21(7):1680-97.

[10]. Andersen AN, Gianaroli L, Felberbaum R, de Mouzon J, Nygren KG; The European IVF-monitoring programme (EIM), European Society of Human Reproduction and Embryology (ESHRE). Assisted reproductive technology in Europe, 2001. Results generated from European registers by ESHRE. Hum Reprod. 2005 May;20(5):1158-76.

[11]. Eskandar, M.:Outcome of twin ICSI pregnancy compared withspontaneous conceived twin pregnancy: a prospective,controlled, observational study(2007), Middle East Fertility Society Journal Vol. 12, No. 2, 2007 Copyright @ Middle East Fertility Society

[12]. Baxi A, Kaushal M Outcome of twin pregnancies conceived after assisted reproductive technique. Journal of Human Reproductive Sciences Issue 1 / Vol. 1 / Jan ,2000, IP: 41.33.236.68

[13]. Filicori M, Cognigni GE, Gamberini E, Troilo E, Parmegiani L, Bernardi S. Impact of medically assisted fertility on preterm birth. BJOG 2005;112:113-7.

[14]. Luke B, Brown MB, Nugent C, Gonzalez-Quintero VH, Witter FR, Newman RB. Risk factors for adverse outcomes in spontaneous versus assisted conception twin pregnancies. FertilSteril 2004;81:315-9.Sutcliffe AG. Health risks in babies born after assisted reproduction.BMJ 2002;325:117-8.

[15]. Daniel Y, Ochshorn Y, Fait G, Geva E, Bar-Am A, Lessing JB. Analysis of 104 twin pregnancies conceived with assisted reproductive technologies and 193 spontaneously conceived twin pregnancies. FertilSteril 2000;74:683-9

[16]. Kallen B, Olausson PO, Nygren KG. Neonatal outcome in pregnancies from ovarian stimulation. ObstetGynecol 2002;100:414-9. 